\title{
Maxillofacial Radiology 172
}

SADJ July 2019, Vol. 74 No. 6 p335

CJ Nortjé

Below are more images of articular disorders which may affect the functioning of the TMJ. Discuss the most important radiological features discernible and what is your diagnosis?
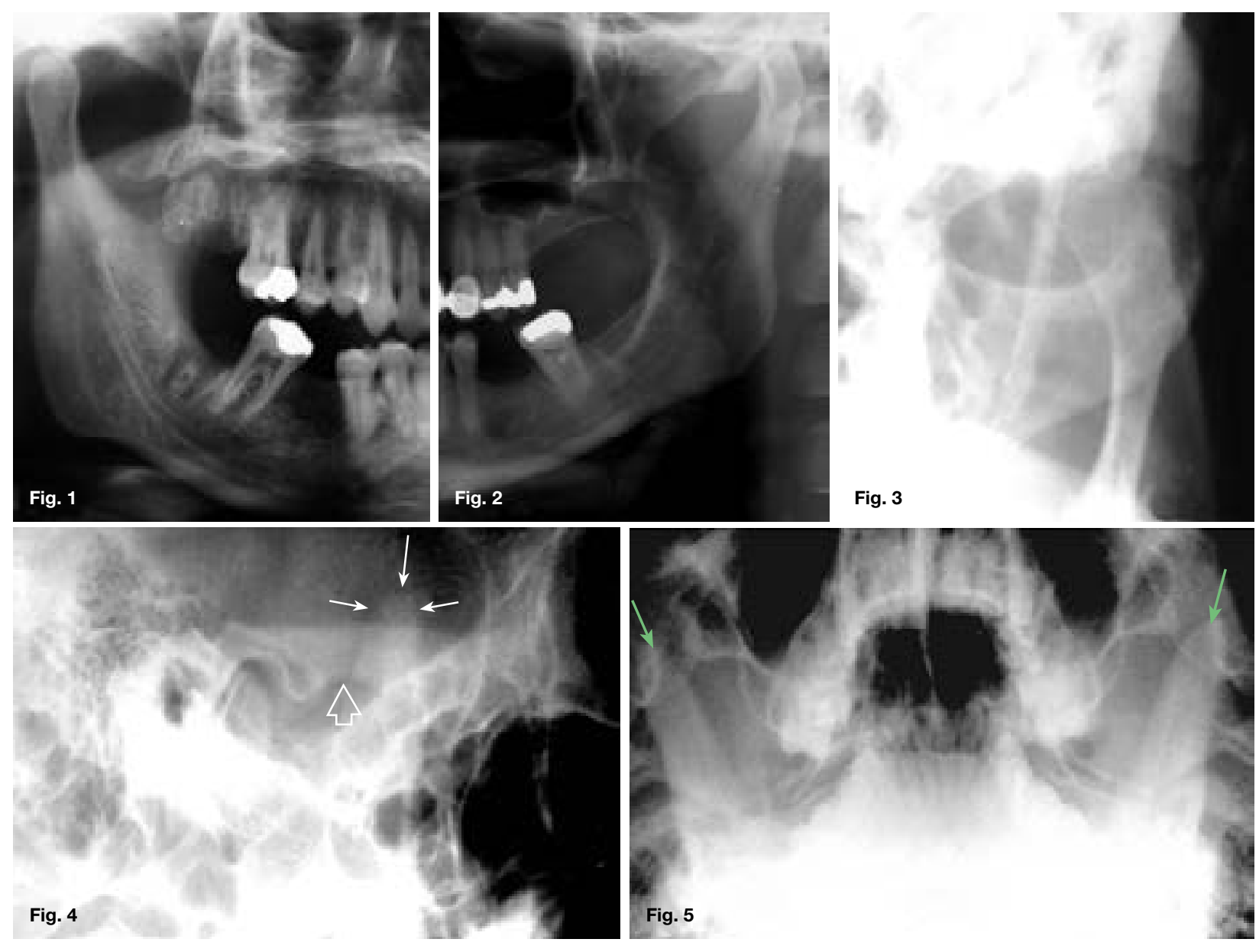

\section{INTERPRETATION}

Figures 1 \& 2 show unilateral hyperplasia of the condylar process, while Figure 3 shows the condyle is enlarged in all directions. Condylar hyperplasia of the mandible is a unilateral progressing hyperplasia of the condyle due to previously accelerated, persistant, or resumed, activity of the precartilagenous cells of the condylar growth zone. The etiology is unknown. Enlargement of one mandibular condylar process may occur in isolation or in association with enlargement of part of the mandibular ramus and body. The condition, either as an isolated finding or as part of hemihyperplasia of the mandible, is usually a coincidental radiological finding. The widespread use of pantomography in dentistry, and to a slightly lesser degree in medicine has facilitated side to side morphological comparisons of the mandible. There is no apparent sex predilection.

Christoffel J Nortjé: $B C h D, P h D, A B O M R, D S c$. Faculty of Dentistry, University of the Western Cape.

ORCID Number: 0000-0002-9717-5514

Email: cnortje@uwc.ac.za

The extent of hyperplasia determines whether it is clinically apparent. There are usually no associated symptoms and the patient is unaware of the situation, although temperomandibular joint dysfuction may present. The cardinal signs of hyperplasia of the condyle are: increased size of the condylar neck and head compared with the normal population or, in unilateral cases, compared with the contralateral side. Figures 4 \& 5 are images of coronoid process hyperplasia. The lateral skull view (Fig. 4) shows major elongation of the coronoid process (closed arrow) well beyond the criteria for elongated process, $1 \mathrm{~cm}$ superior to the inferior border of the zygomatic arch (open arrow) and an inability to move the condyle to the crest of the articular eminence on opening the mouth. The occipitomental view (Fig. 5) also shows major elongation of the coronoid processes (green arrows). Coronoid process hyperplasia is very rare.

\section{Reference}

1. Farman AG, Nortjé CJ, Wood RE: Oral and Maxillofacial Imaging, $1^{\text {st }}$ Ed, Mosby. St. Louis, Missouri 1993 p346-349. 